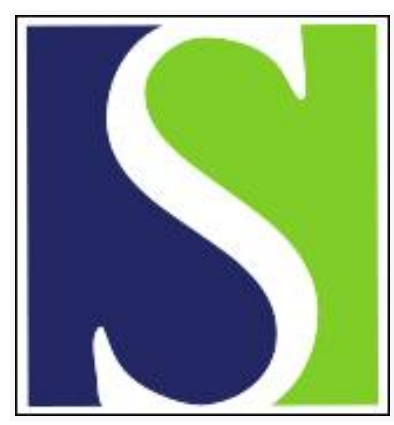

Scand J Work Environ Health 1984;10(3):197-202

https://doi.org/10.5271/sjweh.2350

Issue date: Jun 1984

Development and evaluation of field methods for ammonia in air.

by Rudling J, Hallberg BO, Hultengren M, Hultman A

This article in PubMed: www.ncbi.nlm.nih.gov/pubmed/6236554

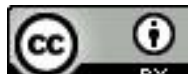




\title{
Development and evaluation of field methods for ammonia in air
}

\author{
by Jan Rudling BSc, Bengt-Olov Hallberg BSc, May Hultengren, Annika Hultman BSc ${ }^{1}$
}

\begin{abstract}
RUDLING J, HALLBERG B-O, HULTENGREN M, HULTMAN A. Development and evaluation of field methods for ammonia in air. Scand $J$ Work Environ Health 10 (1984) 197-202. Three methods for measuring ammonia in air have been evaluated. Filters impregnated with $10 \%$ (volume/volume) phosphoric acid in methanol were used for two methods. Sampling was done either with a filter cassette connected to a pump or with the filters placed in a passive monitor (Gasbadge). The filters were leached with distilled water after the sampling and analyzed with ion chromatography or colorimetry (Nessler). The third method tested was a colorimetric air-monitoring badge system (ProTek). The tests showed that the accuracy of the filter methods is good and that the results are not affected by humidity. If ion chromatography is used for the analysis, amines do not interfere. The Gasbadge monitors increased their uptake when the air velocity over the sampler was raised from 0.2 to $1.0 \mathrm{~m} / \mathrm{s}$. The accuracy of the ProTek method was poor, the method was biased, and blank samples showed high values. In field tests carried out in a foundry and at a fertilizer plant, the agreement between the filter methods was good, whereas the results of the ProTek method deviated drastically from those of the other methods.
\end{abstract}

Key terms: field tests, ion chromatography, passive monitor, sampling.

Ammonia $\left(\mathrm{NH}_{3}\right)$ is used and encountered in various industrial and natural processes. It is used in the manufacture of fertilizers and explosives and as a refrigerant and cleansing agent. Ammonia is a known irritant to respiratory organs, skin, and eyes. In Sweden the standard for occupational exposure to ammonia is $25 \mathrm{ppm}$ (time-weighted average limit) and $50 \mathrm{ppm}$ (ceiling value for a 5 -min period).

The most widely used method for sampling ammonia is the use of midget impingers with dilute sulfuric acid as an absorbing solution followed by analysis with an ion selective electrode or colorimetry $(8$, 12). The disadvantages of using impingers for sampling are well known, and consequently other procedures have been developed. Vincent et al (14) and the National Institute for Occupational Safety and Health (NIOSH) (9) have used silica gel as the adsorbent. Filters impregnated with oxalic acid (1) or sulfuric acid (3) have also been used. The rapid development of passive monitors based on diffusion have resulted in new methods for sampling ammonia. Mazur et al (7) have developed an ammonia dosimeter in which filters impregnated with phosphoric acid are used as collection media. A passive colorimetric air monitoring badge system, ProTek ${ }^{\mathrm{TM}}$ (manufactured by DuPont), has been introduced and documented in a paper (4).

\footnotetext{
1 National Board of Occupational Safety and Health, Stockholm, Sweden.
}

Reprint requests to: Mr J Rudling, National Board of Occupational Safety and Health, S-171 84 Solna, Sweden.
For analysis, the most widely employed methods are colorimetry or the ion selective electrode but in the last several years ion chromatography has been available as a valuable tool to improve sensitivity and selectivity. The method has been used for analyzing the ammonium ion in aerosols (11).

Although one inherent drawback of the method is the high cost of instrumentation, it is possible to use ordinary equipment for high-performance liquid chromatography with minor supplementation for ion chromatographic analysis (5).

The purpose of this work was to perform a comparison study in the laboratory, as well as in the field, for three different methods, a filter method developed at our laboratory, a passive filter method that is a modification of the method proposed by Mazur et al, and the ProTek method. Silica gel tubes were excluded from the study since purchased tubes showed high backgrounds and a prestudy demonstrated that impregnated filters have higher capacity and recovery.

\section{Materials and methods}

\section{Sampling and analysis}

For the filter method the following procedure is used. Filters (support pads Millipore AP 10, $37 \mathrm{~mm}$ ) are dipped in $10 \%$ phosphoric acid $[10 \mathrm{ml}$ of phosphoric acid is diluted to $100 \mathrm{ml}$ with methanol (analytical purity)], allowed to drip off, and dried at $60^{\circ} \mathrm{C}$ for $1 \mathrm{~h}$. Treated filters should be stored dry prior to 
usage. Sampling is done by loading the filters in an ordinary casette and connecting the device to a pump with a flow rate of $1.0 \mathrm{l} / \mathrm{min}$, the sampling period being up to $4 \mathrm{~h}$. If a longer storage period is necessary, refrigeration is recommended. After the sampling, the filters are leached with $50 \mathrm{ml}$ of distilled water and shaken gently for $5 \mathrm{~min}$, and after filtration of an aliquot analysis is made by ion chromatography.

Other methods such as colorimetry (Nessler) or the ion selective electrode could also be used for the analysis.

Filters for the passive filter method are prepared in a similar way. Filters $(38 \times 44 \mathrm{~mm})$ are cut from a disc (Millipore AP 10, $142 \mathrm{~mm}$ ), and after impregnation they are put in Gasbadge monitors. This type of monitor has been described in several papers $(7,13)$. After sampling, the analysis is made with the same procedure used for the first filter method presented. If we assume that the sorbent acts as a perfect sink, the sampling rate, $f$ (in $\mathrm{cm}^{3} / \mathrm{min}$ ), for a passive monitor is given by (6):

$$
f=(D \times A \times 60) / L
$$

where $\mathrm{D}=$ the diffusion coefficient $\left(\mathrm{cm}^{2} / \mathrm{s}\right), \mathrm{L}=$ diffusive path $(\mathrm{cm})$, and $A=$ cross-section area of the sampler $\left(\mathrm{cm}^{2}\right)$.

For practical reasons the sampling rate is usually determined from exposure of the samplers to known

Table 1. Ion chromatographic conditions

\begin{tabular}{ll}
\hline Parameter & Material used/setting \\
\hline Columns & $4-\times-50-\mathrm{mm}$ Dionex trap column \\
& $4-\times-50-\mathrm{mm}$ Dionex cation concentrator \\
& $4-\times-250-\mathrm{mm}$ Dionex cation separator \\
& $9-\times-100-\mathrm{mm}$ Dionex cation suppressor \\
Flow & $138 \mathrm{~m} 1 / \mathrm{h}$ \\
Eluent & $0.005 \mathrm{~mol} / 1$ of hydrochloric acid \\
Sample volume & $100 \mu !$ \\
Detector & Conductivity \\
Sensitivity & 10 or $30 \mu \mathrm{mho}$ full.scale \\
\hline
\end{tabular}

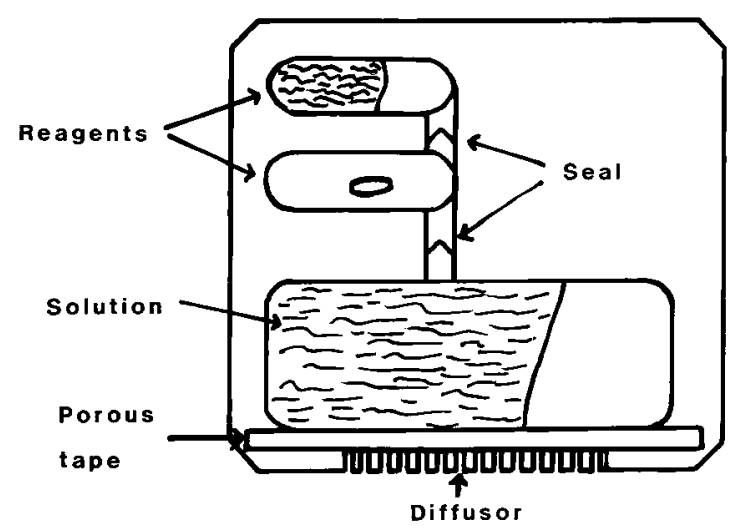

Figure 1. Protek sampler for ammonia. concentrations of ammonia in air. Mazur et al determined the sampling rate to be $96.2 \mathrm{~cm}^{3} / \mathrm{min}$, and we initially used the same value. This rate is good for $25^{\circ} \mathrm{C}$. A temperature correction can be made by:

$$
f\left(t^{\circ} \mathrm{C}\right)=f\left(25^{\circ} \mathrm{C}\right) \times\left(\frac{\mathrm{t}+273}{298}\right)^{1,5} .
$$

For the analysis a Dionex 14 ion chromatograph equipped with an Altex Chromatopac integrator has been used. The ion chromatographic conditions are given in table 1. The limit of detection is below 10 $\mu \mathrm{mol} / 1$, and the calibration curve is linear up to 200 $\mu \mathrm{mol} / 1$ with a standard deviation of about $2 \mu \mathrm{mol} / 1$. If the coefficient of variation $(\mathrm{CV})$ is to be $\leq 10 \%$, the smallest amount to be quantified is $20 \mu \mathrm{mol} / 1$. With the outlined procedure and a 5-1 air sample, 5 ppm can be analyzed by the filter method. If an 8-h sample is taken for the passive filter method, $0.5 \mathrm{ppm}$ is the limit. These limits could be extended by an increase in the injection volume. The Nessler method has been used for some analyses, and we have used the procedure given by Skare \& Stomrud (12), which is equivalent to that given by NIOSH (8).

The ProTek system is also based on diffusion. Gas molecules enter the sampler (see figure 1) through a diffusor and a porous tape into an absorbing solution containing $0.1 \mathrm{~mol} / \mathrm{l}$ of boric acid and $0.03 \mathrm{~mol} / \mathrm{l}$ of sodium potassium tartrate solution. The color reagent used for the analysis is a modification of Nessler's reagent for ammonia. The analysis involves pressing the reagent blisters and making the reagents mix with the absorbing solution. The intensity of the color formed is then determined after the sampler, made of a transparent material, is inserted into a specially designed photometer (PT-3). The result is given directly in parts per million times hours. Calibration is accomplished by the use of two calibration cards, span and zero. The range of the method is $50-500 \mathrm{ppm} \times \mathrm{h}$. The sensitivity can be improved if the analysis is carried out with the spectrophotometric method supplied by the manufacturer.

\section{Generation of test atmospheres}

Ammonia was generated in dynamic systems by the dilution of concentrated gas from a cylinder. For tests of the filter method a certified gas cylinder containing 2,100 ppm of ammonia in nitrogen was used. The flow rate from the cylinder was controlled by a mass flowmeter (Brooks) calibrated against a soap bubble meter. Clean and dry house air, measured via a calibrated rotameter, was used for dilution; it was mixed with the contaminant stream in a 5-1 glass bulb and passed forward to a manifold equipped with eight outlet ports for the filters to be tested. For the sampling the filters were connected to a pump via critical orifices.

For a test of the passive filter method and the ProTek procedure a similar generation system was used 
(see figure 2). The cylinder used contained $32,000 \mathrm{ppm}$ of ammonia in nitrogen and the flow rate of the air was $100 \mathrm{l} / \mathrm{min}$. The monitors to be tested were placed in a glass tube (length $=1,300 \mathrm{~mm}$, diameter $=93$ $\mathrm{mm}$ ) at least $150 \mathrm{~mm}$ apart. Under these conditions an air velocity of $0.24 \mathrm{~m} / \mathrm{s}$ was achieved and used, with some stated exceptions, throughout the tests.

The certified cylinder contents were controlled by the passing of a known amount of gas through a fritted bubbler bottle containing dilute hydrochloric acid with methyl red as the indicator. The time required for the color to change to neutral was registered. The results from the analysis of the two cylinders showed excellent agreement with the certificate supplied by the manufacturer (Alfax).

As an additional control of the test atmosphere a set of seven impinger samples containing $15 \mathrm{ml}$ of $0.0025-\mathrm{mol} / \mathrm{l}$ sulfuric acid were taken with each run and analyzed with ion chromatography. The average of these samples was not allowed to deviate more than $\pm 5 \%$ from the calculated value. Of a total of 12 runs, one run exceeded the limit and was thus discarded. The average of the remaining 11 runs yielded $99.1 \%$ of the calculated value with a $\mathrm{CV}$ of $3.2 \%$.

For the generation of humidity, the air stream was passed through fritted bubblers with distilled water. The relative humidity $(\mathrm{RH})$ was controlled with a humidity meter (Vaisala humicap). As a standard condition $10-15 \% \mathrm{RH}$ and $20^{\circ} \mathrm{C}$ was used. Sampling time was about $4 \mathrm{~h}$ for the filter method and about $8 \mathrm{~h}$ for the passive filter method and the ProTek procedure.

\section{Results and discussion}

The collection efficiency for the filter method was determined by the following process: an impinger with $0.0025-\mathrm{mol} / \mathrm{l}$ sulfuric acid was connected after a filter, $25 \mathrm{ppm}$ of ammonia was sampled for various times, and the proportion collected on the filter (= collection efficiency) was determined. A collection efficiency of $>99 \%$ was achieved. The capacity of the filters was determined from the sampling of 50 ppm of ammonia, for which the time was recorded when a breakthrough of $>5 \%$ occurred. This event took place after $6-8 \mathrm{~h}$, which means that the capacity for the filters is at least $300 \mathrm{ppm} \times \mathrm{h}$.

In tables $2-4$ recovery and precision for the three methods are given. Each method was tested at three different concentrations. For the filter method additional tests were carried out. For evaluation we have used the criteria adopted by NIOSH (2); therefore we should be able with $95 \%$ confidence to state that a single result is within $\pm 25 \%$ of the true value. This criteria can be expressed as "overall system accuracy (OSA)" (6) according to:

$$
\mathrm{OSA}=|\overline{\mathrm{x}}-100|+2 \times \overline{\mathrm{CV}} \leq 25 \%,
$$

where $\overline{\mathrm{x}}=$ average recovery in percent and $\overline{C V}=$ pooled coefficient of variation in percent.

For the filter method we have assumed that the usage of a portable pump for sampling increases the CV. (In the tests critical orifices were used.) We have estimated the $\mathrm{CV}$ for a pump to be $5 \%$. Therefore, the $\overline{\mathrm{CV}}$ in table 2 should be corrected to:

$$
\overline{\mathrm{CV}}=\sqrt{2.3^{2}+5^{2}}=5.5 \% \text {. }
$$

If we use this value for the filter method, OSA equals $11 \%$. We can also see from table 2 that shorttime samples could be taken with high accuracy and that an alternative method of analysis (Nessler) yields good results. High humidity does not influence the method. Since the passive filter method uses the same type of sorbent, high humidity should not present any problem for that method.

The passive filter method is also in compliance with the NIOSH criteria, OSA equaling $10 \%$. Since the recovery is slightly less than $100 \%$, we have corrected the initial sampling rate, and, in the following discussion, we use $94 \mathrm{~cm}^{3} / \mathrm{min}$. For the ProTek method OSA equals $37 \%$, and it is obvious from table 4 that the method is biased. Another fact to be noticed is that the method shows a high background when blank samples are run. This background in-

Figure 2. Apparatus used for generating the test atmospheres.

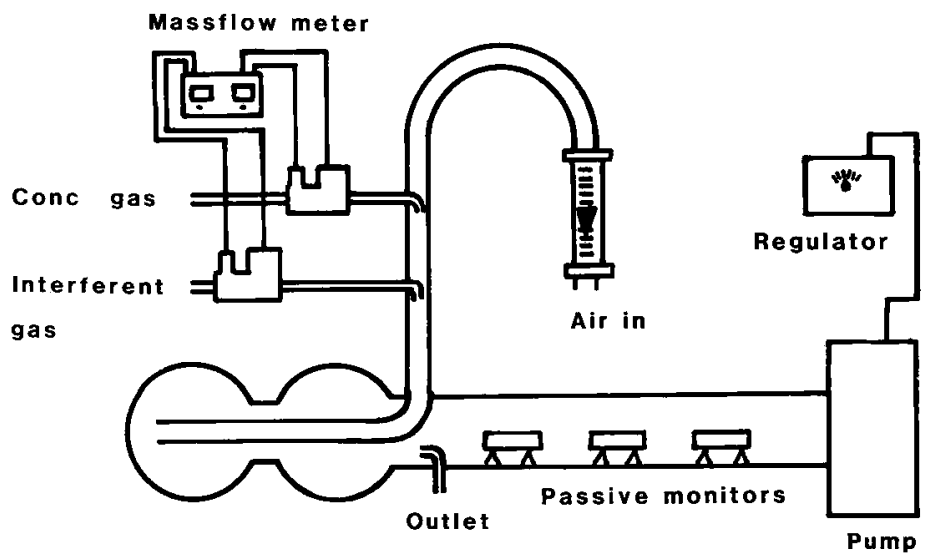


creases with storage time prior to usage. We have subtracted the background from the results. This procedure is not recommended in the manufacturer's instructions, and, if the method is used the normal way, an additional bias would be registered.

We repeated the experiments for the ProTek method with another lot of badges that were exposed to $21.0 \mathrm{ppm}$ for $6 \mathrm{~h}$. This time the analysis showed 72 ppm $\times \mathrm{h}$ with the readout unit (PT-3) and 76 $\mathrm{ppm} \times \mathrm{h}$ when analyzed with a spectrophotometer. This finding indicates that the calibration factor supplied by the manufacturer is not correct. This inaccuracy was confirmed through the procedure of injecting known amounts of ammonium ion solution

Table 2. Recovery and precision for the filter method.

\begin{tabular}{lcccc}
\hline Run & $\begin{array}{c}\text { Ammonia } \\
\text { taken } \\
(\mathrm{ppm})\end{array}$ & $\begin{array}{c}\text { Recovery } \\
(\%)\end{array}$ & $\begin{array}{c}\text { Coefficient } \\
\text { of variation } \\
(\%)\end{array}$ & $\mathrm{N}$ \\
\hline $1^{\mathrm{a}}$ & 12.0 & 96 & 2.2 & 6 \\
$2^{\mathrm{a}}$ & 25.0 & 102 & 1.6 & 6 \\
$3^{\mathrm{a}}$ & 50.0 & 100 & 3.0 & 6 \\
$4^{\mathrm{b}}$ & 25.0 & 99 & 1.0 & 6 \\
$5^{\mathrm{c}}$ & 9.4 & 97 & 0.8 & 6 \\
$6^{\text {d }}$ & 25.0 & 98 & 0.8 & 5 \\
$7^{\mathrm{b}, \mathrm{d}}$ & 25.0 & 104 & 1.3 & 5 \\
\hline
\end{tabular}

a Average recovery $=100 \%$ (run $1-3$ ); pooled coefficient of variation $=2.3 \%$ (run $1-3$ ).

b Analyzed with the Nessler method.

c Short-time samples (5 min).

High humidity ( $\mathrm{RH}=80 \%$ ).

Table 3. Recovery and precision for the passive filter method.

\begin{tabular}{lcccc}
\hline Run $^{\mathrm{a}}$ & $\begin{array}{c}\text { Ammonia } \\
\text { taken } \\
(\mathrm{ppm})\end{array}$ & $\begin{array}{c}\text { Recovery } \\
(\%)\end{array}$ & $\begin{array}{c}\text { Coefficient } \\
\text { of variation } \\
(\%)\end{array}$ & $\mathrm{N}$ \\
\hline 1 & 6.1 & 95 & 3.3 & 6 \\
2 & 23.0 & 106 & 4.1 & 6 \\
3 & 47.0 & 92 & 4.6 & 6 \\
\hline
\end{tabular}

a Average recovery $=98 \%$; pooled coefficient of variation $=4.0 \%$. into the badges. Our conclusion is that the sampling system works well for ProTek, but the analytical reagents cannot be stored for a longer period and/or transported by air to Sweden.

Storage stability for the methods are shown in table 5. Each result is the average of three samples. The loss for the filter method is less than $10 \%$ over a five-week period when samples are stored in a refrigerator. The increase noticed for ProTek is most likely due to an increase in background. The storage time is not representative and is explained by the fact that the readout unit was changed, with a resulting delay.

Common interferents for ammonia are amines. Known amounts of three different amines were generated by the injection of liquid solutions of amines with a motor driven syringe into an air stream containing $25 \mathrm{ppm}$ of ammonia. The samples were collected by the filter method and analyzed with ion chromatography and by the Nessler method. The results are given in table 6 . The Nessler method is influenced to a moderate degree $(+16 \%)$. Since these amines have longer retention times than the ammonium ion, they do not interfere with the ion chromatographic determination. In many sampling situations amines should not present any problem when analyzed by the Nessler method. This is probably also true for ProTek since the same method (modified Nessler) is used for the analysis.

Passive monitors are, to a certain degree, dependent on the velocity of the air passing over the opening area of the sampler (face velocity). From table 7 we can see that the passive monitors, type Gasbadge, used for the passive filter method, increased their uptake as the velocity increased, whereas for the ProTek system it seems that the opposite is true. Our interpretation is that the ProTek system is unaffected within the range that was tested.

Most evaluations concerning passive monitors have been done with a constant face velocity, often

Table 4. Recovery and precision for ProTek.

\begin{tabular}{lccccc}
\hline Run & $\begin{array}{c}\text { Ammonia taken } \\
(\mathrm{ppm})\end{array}$ & $\begin{array}{c}\text { Background } \\
(\mathrm{ppm} \times \mathrm{h})\end{array}$ & $\begin{array}{c}\text { Recovery } \\
(\%)\end{array}$ & $\begin{array}{c}\text { Coefficient of variation } \\
(\%)\end{array}$ & $\mathrm{N}$ \\
\hline 1 & 6.1 & 36 & 113 & 8.1 & $6^{\mathrm{C}}$ \\
2 & 22.6 & 26 & 117 & 11.0 & 6 \\
3 & 46.8 & 60 & 127 & 6.9 & $6^{c}$ \\
\hline
\end{tabular}

average recovery $=119 \%$; pooled coefficient of variation $=8.8 \%$.

b Background deducted from the results.

c One sampler burst during analysis.

Table 5. Storage stability.

\begin{tabular}{|c|c|c|c|c|c|c|}
\hline \multirow{2}{*}{ Method } & \multirow{2}{*}{$\begin{array}{l}\text { Ammonia taken } \\
(\mathrm{ppm})\end{array}$} & \multirow{2}{*}{$\begin{array}{l}\text { Relative humidity } \\
\qquad(\%)\end{array}$} & \multicolumn{4}{|c|}{ Recovery $(\%)$ after storage } \\
\hline & & & 0 weeks & 2 weeks & 5 weeks & 8 weeks \\
\hline Filter method & 25 & 15 & 100 & 99 & 93 & v \\
\hline Filter method & 25 & 80 & 100 & .. & 91 & \\
\hline ProTek & 25 & 20 & 100 & .. & .. & 118 \\
\hline
\end{tabular}


Table 6. Effect of interferences of amines.

\begin{tabular}{lcccccc}
\hline \multirow{2}{*}{ Method } & \multirow{2}{*}{$\begin{array}{c}\text { Ammonia taken } \\
(\mathrm{ppm})\end{array}$} & \multicolumn{4}{c}{ Recovered amount (ppm) } \\
\cline { 3 - 7 } & 25 & Methylamine & Diethylamine & Triethylamine & Ammonia & N \\
\hline lon chromatography & 25 & 17 & 20 & 7 & 24 & 3 \\
Nessler & & $\cdot$ & $\cdot$ &. & 29 & 3 \\
\hline
\end{tabular}

Table 7. Influence of air velocity on passive monitors.

\begin{tabular}{|c|c|c|c|c|c|}
\hline Method & $\begin{array}{l}\text { Ammonia taken } \\
(\mathrm{ppm})\end{array}$ & $\begin{array}{l}\text { Air velocity } \\
(\mathrm{m} / \mathrm{s})\end{array}$ & $\begin{array}{l}\text { Recovery } \\
(\%)\end{array}$ & $\begin{array}{c}\text { Coefficient of variation } \\
(\%)\end{array}$ & $N$ \\
\hline $\begin{array}{l}\text { Passive filter method } \\
\text { Passive filter method } \\
\text { ProTek } \\
\text { ProTek }\end{array}$ & $\begin{array}{l}26.4 \\
26.2 \\
28.0 \\
24.8\end{array}$ & $\begin{array}{l}0.09 \\
1.0 \\
0.09 \\
1.0\end{array}$ & $\begin{array}{r}76 \\
124 \\
139^{\mathrm{a}} \\
123^{\mathrm{a}}\end{array}$ & $\begin{array}{r}6.5 \\
5.2 \\
13.1 \\
12.0\end{array}$ & $\begin{array}{l}6 \\
6 \\
6 \\
6\end{array}$ \\
\hline
\end{tabular}

a Background $60 \mathrm{ppm} \times \mathrm{h}$ deducted from the results.

Table 8. Average results from field samples. ( $\mathrm{S}=$ stationary samples, $\mathrm{P}=$ personal samples, $\mathrm{CV}=$ coefficient of variation)

\begin{tabular}{|c|c|c|c|c|c|c|c|}
\hline \multirow[b]{2}{*}{ Location } & \multirow[b]{2}{*}{$N$} & \multicolumn{2}{|c|}{ Filter method } & \multicolumn{2}{|c|}{ Passive filter method } & \multicolumn{2}{|c|}{ ProTek ${ }^{-}$} \\
\hline & & $\begin{array}{c}\text { Ammonia } \\
(\mathrm{ppm})\end{array}$ & $\begin{array}{l}\mathrm{CV} \\
(\%)\end{array}$ & $\begin{array}{c}\text { Ammonia } \\
\text { (ppm) }\end{array}$ & $\begin{array}{l}\text { CV } \\
(\%)\end{array}$ & $\underset{(\mathrm{ppm})}{\operatorname{Ammonia}}$ & $\begin{array}{l}\mathrm{CV} \\
(\%)\end{array}$ \\
\hline $\begin{array}{l}\text { Fertilizer plant }(S) \\
\text { Foundry }(S) \\
\text { Fertilizer plant }(P)+\text { foundry }(P)\end{array}$ & $\begin{array}{r}10 \\
12 \\
9\end{array}$ & $\begin{array}{l}12.2 \\
1.24 \\
3.5\end{array}$ & $\begin{array}{c}7.4 \\
6.5 \\
.\end{array}$ & $\begin{array}{c}11.9 \\
1.64 \\
3.8\end{array}$ & $\begin{array}{c}6.6 \\
24\end{array}$ & $\begin{array}{r}26 \\
<7 \\
13\end{array}$ & $\begin{array}{c}10.4 \\
\cdot \\
\cdot\end{array}$ \\
\hline
\end{tabular}

a Background $53 \mathrm{ppm} \times \mathrm{h}$ deducted from the results.

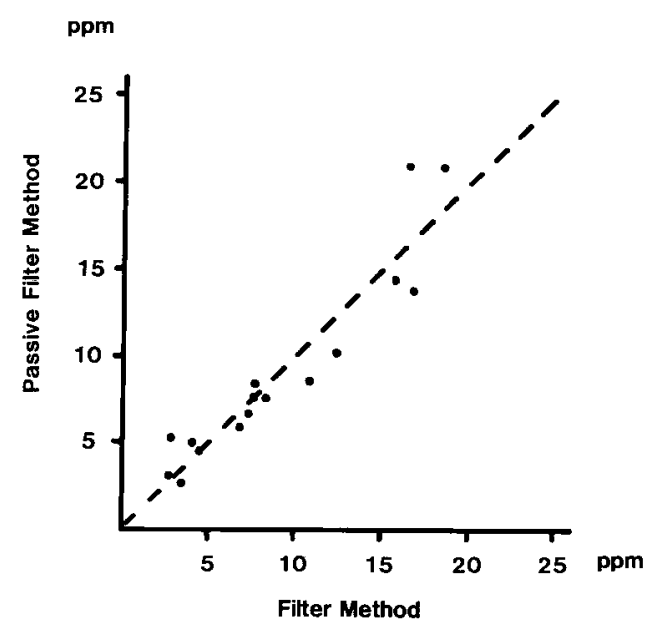

Figure 3. Field tests: Passive filter method versus the filter method.

around $0.5 \mathrm{~m} / \mathrm{s}$. Tompkins \& Goldsmith (13) claim that face velocities above $0.08 \mathrm{~m} / \mathrm{s}$ do not influence the uptake for Gasbadge, but they present no data to support this argument. Samimi \& Falbo (10) have found that for styrene the uptake in a Gasbadge monitor increases $27 \%$ when the face velocity is increased from 0.06 to $0.36 \mathrm{~m} / \mathrm{s}$. Obviously more research is needed in this area. In the field, we are likely

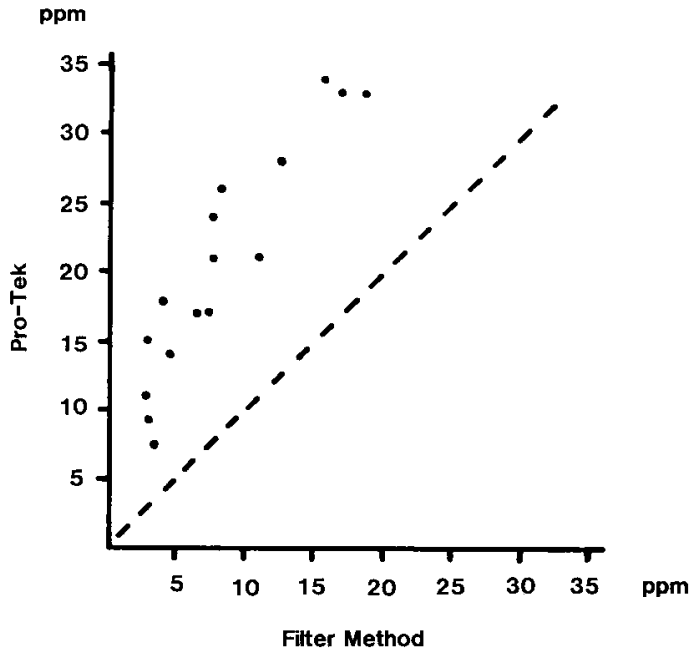

Figure 4. Field tests: ProTek versus the filter method.

to encounter velocities in the range of 0.1 to $1 \mathrm{~m} / \mathrm{s}$ (Lars Olander, personal communication).

Our study was completed by field tests in two different environments, a fertilizer plant and a foundry. At every plant six stationary and six personal sampling sites were picked out (sampling time $8 \mathrm{~h}$ ). The stationary samples were taken as duplicates and the sampling devices were mounted on a rack (with a 
maximum distance of $40 \mathrm{~cm}$ between the samplers) with randomized positions of the samplers. The personal samples were taken with samplers affixed as close as possible to each other. The results are summarized in table 8. Due to pump malfunction some samples were discarded.

The CV for the methods to be tested was calculated for each plant from the stationary samples according to:

$$
\mathrm{CV}=\frac{100}{\overline{\mathrm{x}}} \times \sqrt{\frac{\Sigma \mathrm{d}_{\mathrm{i}}^{2}}{\mathrm{n}}}
$$

where $\bar{x}=$ mean value in parts per million, $d_{i}=$ difference in parts per million between duplicates, and $\mathrm{n}=$ number of samples.

With the actual set-up of the field tests it is probably more correct to estimate the $\mathrm{CV}$ from a logarithmic transformation of the data since the standard deviation for an air sampling method is usually proportional to the mean (constant CV). However, the difference between such an estimation and the proposed one (which is simpler) is in this case insignificant.

In figures 3 and 4 the individual values for the passive filter method and the ProTek system are plotted against the values obtained by the filter method. Values below $2.5 \mathrm{ppm}$ ( $=10 \%$ of the Swedish standard) have been omitted. Agreement was good between the two filter methods although at the foundry the passive filter method showed significantly higher values than the filter method. The ProTek method demonstrated a drastic deviation from the other methods in spite of the fact that a background of $53 \mathrm{ppm} \times \mathrm{h}$ was deducted from the results. As can be seen from figure 4 , there is a distinct pattern indicating that, if an additional background is deducted and another calibration factor is used, better agreement would be obtained.

\section{Conclusions}

Both the laboratory and field tests showed that the two filter methods are in compliance with standards that could be set up for a field method. As has been demonstrated by the laboratory tests, high air velocities could be a problem for passive monitors like the Gasbadge. The ProTek system is, in its present state, not usable as a field method. But it must be stressed that it is our belief that the method is basically sound and that it can be improved if the sampling and analysis are separated and the users prepare their own reagents and calibration curves.

\section{References}

1. Adachi K, Makino H, Kaneko M. Determination of odorous substances: II Determination of ammonia. Kanagawaken Kogai Senta Nempo 11 (1980) 17. (Cited in Analytical Abstracts 41 (1981): 3B, 147).

2. Gunderson E, Anderson C. Development and validation of methods for sampling and analysis of workplace toxic substances. US Department of Health \& Human Services, Cincinnati, OH 1980. (DHHS (NIOSH) publ no 80-133).

3. Kenmochi S, Ishii K. Ammonia determination by sulphate-treated filter-papers. Okayama-ken Kankyo Hoken Senta Nempo 3 (1979) 103-105. (Cited in Analytical Abstracts 40 (1981): $3 \mathrm{H}, 17$ ).

4. Kring E, Lautenberger W, Baker B, Douglas J, Hoffman R. A new passive colorimetric air monitoring badge system for ammonia, sulfur dioxide and nitrogen dioxide. Am Ind Hyg Assoc J 42 (1981) 373-381.

5. Lagesson W. Förenklade jonkromatografiska metoder för bestämning av oorganiska substanser med yrkeshygieniska och omgivningshygieniska intressen. Yrkesmedicinska kliniken, Regionsjukhuset, Linköping 1982.

6. Lautenberger W, Kring E, Morello J. A new personal badge monitor for organic vapors. Am Ind Hyg Assoc J 41 (1980) 737-746.

7. Mazur JF, Bamberger RL, Podolak GE, Esposito GG. Development and evaluation of an ammonia dosimeter. Am Ind Hyg Assoc J 39 (1978) 749-753.

8. National Institute for Occupational Safety and Health. Manual of analytical methods. Volume 1 (P \& C AM 205). US Department of Health, Education and Welfare, Cincinnati, OH 1977. (DHEW (NIOSH) publ no 77-157A)

9. National Institute for Occupational Safety and Health. Manual of analytical methods. Volume 5 (s 347). US Department of Health, Education and Welfare, Cincinnati, OH 1979. (DHEW (NIOSH) publ no $79-141)$.

10. Samimi BS, Falbo L. Comparison of standard charcoal tubes with Abcor organic vapor dosimeters within controlled atmosphere. Paper presented at the American Industrial Hygiene Conference in 1982 in Cincinnati, $\mathrm{OH}$.

11. Sawicki E, Mulik JD, Wittgenstein E. Ion chromatographic analysis of environmental pollutants. Ann Arbor Science Publishers, Ann Arbor, MI 1978.

12. Skare I, Stomrud AM. Bestämning av ammoniak i luft. Arbetarskyddsstyrelsen, Stockholm 1974. (Undersökningsrapport AMTG 105/74).

13. Tompkins FC, Goldsmith RL. A new personal dosimeter for the monitoring of environmental pollutants. Am Ind Hyg Assoc J 38 (1977) 371-377.

14. Vincent WJ, Kahn KJ, Ketcham NH. Determining ammonia in the presence of airborne concentrations of ethylenediamine and monoethanolamine. Am Ind Hyg Assoc J 39 (1978) 502-506.

Received for publication: 24 October 1983 